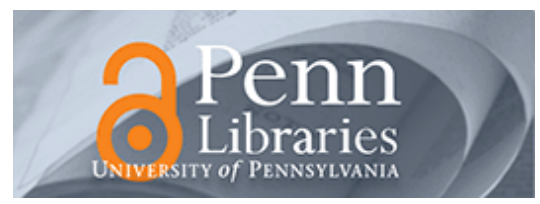

University of Pennsylvania

ScholarlyCommons

Business Economics and Public Policy Papers

Wharton Faculty Research

2014

\title{
What Happens the Morning After? The Costs and Benefits of Expanding Access to Emergency Contraception
}

Tal Gross

Jeanne Lafortune

Corinne Low

Follow this and additional works at: https://repository.upenn.edu/bepp_papers

Part of the Business Commons, Economics Commons, and the Public Affairs, Public Policy and Public Administration Commons

\section{Recommended Citation}

Gross, T., Lafortune, J., \& Low, C. (2014). What Happens the Morning After? The Costs and Benefits of Expanding Access to Emergency Contraception. Journal of Policy Analysis and Management, 33 (1), 70-93. http://dx.doi.org/10.1002/pam.21731/abstract

This paper is posted at ScholarlyCommons. https://repository.upenn.edu/bepp_papers/45

For more information, please contact repository@pobox.upenn.edu. 


\title{
What Happens the Morning After? The Costs and Benefits of Expanding Access to Emergency Contraception
}

\author{
Abstract \\ Emergency contraception (EC) can prevent pregnancy after sex, but only if taken within 72 hours of \\ intercourse. Over the past 15 years, access to EC has been expanded at both the state and federal level. \\ This paper studies the impact of those policies. We find that expanded access to EC has had no \\ statistically significant effect on birth or abortion rates. Expansions of access, however, have changed the \\ venue in which the drug is obtained, shifting its provision from hospital emergency departments to \\ pharmacies. We find evidence that this shift may have led to a decrease in reports of sexual assault \\ Disciplines \\ Business | Economics | Public Affairs, Public Policy and Public Administration
}




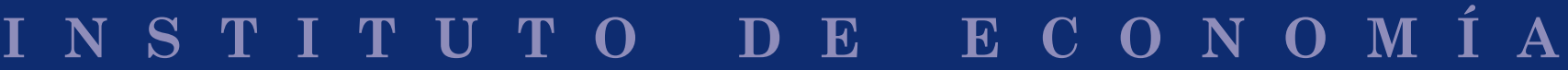
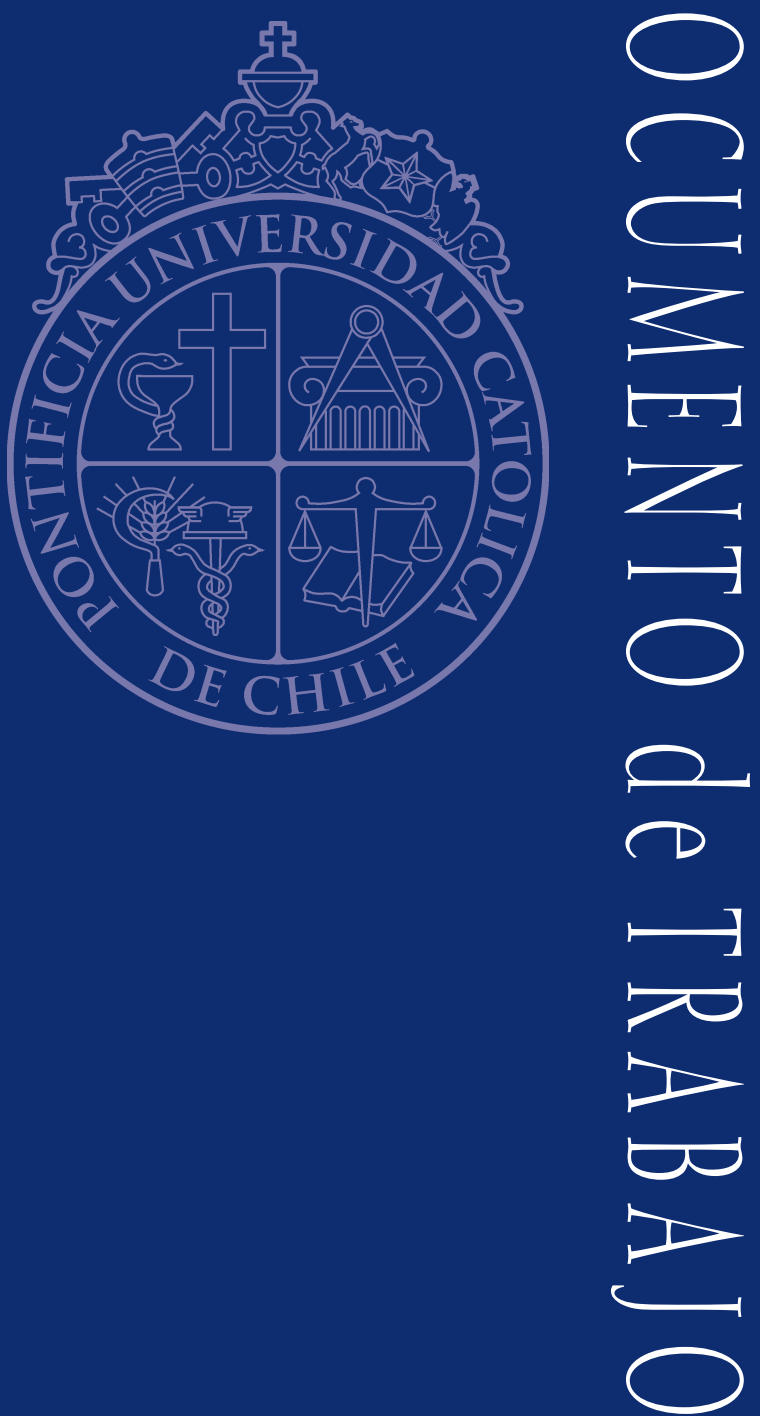

What Happens the Morning After? The Costs and Benets of Expanding Access to Emergency Contraception

Tal Grossy, Jeanne Lafortune, Corinne Low. 
Versión impresa ISSN: 0716-7334

Versión electrónica ISSN: 0717-7593

PONTIFICIA UNIVERSIDAD CATOLICA DE CHILE

INSTITUTO DE ECONOMIA

Oficina de Publicaciones

Casilla 76, Correo 17, Santiago

www.economia.puc.cl

WHAT HAPPENS THE MORNING AFTER? THE COSTS AND BENE_TS OF EXPANDING ACCESS TO EMERGENCY CONTRACEPTION

Tal Gross

Jeanne Lafortune*

Corinne Low

Documento de Trabajo $N^{\circ} 425$

Santiago, Abril 2012

*jlafortune@uc.cl 


\section{INDEX}

\section{ABSTRACT}

INTRODUCTION

2. THEORETICAL FRAMEWORK

2.1 Structure of the Model

5

2.2 The Effect of Emergency Contraception

2.3 Emergency Contraception versus Traditional Contraception

2.4 Victims of Sexual Assault

4. RESULTS

4.1 Births and Abortions 


\title{
What Happens the Morning After? The Costs and Benefits of Expanding Access to Emergency Contraception*
}

\author{
Tal Gross ${ }^{\dagger} \quad$ Jeanne Lafortune ${ }^{\ddagger} \quad$ Corinne Low ${ }^{\S}$
}

April 2012

\begin{abstract}
Emergency contraception (EC) can prevent pregnancy after sex, but only if taken within 72 hours of intercourse. Over the past 15 years, access to EC has been expanded at both the state and federal level. This paper studies the impact of those policies. We find that expanded access to EC has had no statistically significant effect on birth or abortion rates. Expansions of access, however, have changed the venue in which the drug is obtained, shifting its provision from hospital emergency departments to pharmacies. We find evidence that this shift may have led to a decrease in reports of sexual assault.
\end{abstract}

JEL classification: J13, I18

Key words: Emergency contraception, Fertility, Abortion, Sexual assault

*We are grateful to Melissa Kearney, Cristian Pop-Eleches, Douglas Almond, James Trussell, and Theodore Joyce for helpful comments. Mattias Antonio and Jose Carreño provided research assistance. Low thanks the National Science Foundation for support.

${ }^{\dagger}$ Columbia University, tg2370@columbia.edu

‡Pontificia Universidad Católica de Chile, jlafortune@uc.cl

$\S$ Columbia University, csl2137@columbia.edu 


\section{Introduction}

In the 1960s, the introduction of oral contraception had a profound impact on women's fertility, education, and labor market outcomes (Goldin and Katz, 2002; Bailey, 2006). Oral contraception, however, requires that women obtain a prescription and consume pills on a daily basis in order to prevent pregnancy. This paper studies the impact of increasing access to a different form of contraception, emergency contraception (EC), more commonly known as the "morning-after pill." EC, unlike oral contraception, is effective when taken within 72 hours following intercourse. While EC cannot be used on a daily basis, it offers women a chance to avert pregnancy after intercourse, when previously their only options would have been either abortion or carrying the pregnancy to term.

Access to EC has changed dramatically in the last 15 years. Early forms of EC were pioneered in the 1970s, but their existence was not widely known. ${ }^{1}$ It was not until 1997 that the Food and Drug Administration (FDA) first approved a commercial EC product in the United States, Preven, available by prescription only. In 1999, "Plan B," the most widely known form of EC, was introduced, and was also only available with a prescription. At the time of EC's introduction, researchers and policy-makers alike were optimistic about its potential to prevent unintended pregnancies and abortion (Trussell et al., 2004). A 2002 Guttmacher Institute report estimated that EC had been responsible for a "substantial proportion" of the decline in abortion rates over the last decade, estimating that EC had averted 51,000 abortions in 2000 alone (Jones et al., 2002). This technology was expected to be especially instrumental in preventing pregnancy from sexual assault; Trussell and Stewart (2000) estimate that provision of EC following assault could have prevented 22,000 of the 25,000 pregnancies resulting from reported assaults in 1998.

To be effective, EC must be taken soon after intercourse. Because of this, various

\footnotetext{
${ }^{1}$ Ellertson (1996) summarizes the early history of EC. Initially, EC was simply an off-label use of traditional oral contraceptives and intra-uterine devices.
} 
policies have been put in place since 1997 to increase access to EC. Between 1997 and 2007, 9 states allowed pharmacists to directly dispense EC without a prescription and regardless of the patient's age. ${ }^{2}$ We call such laws "pharmacy-access laws." Furthermore, 16 states, plus the District of Columbia, mandated that hospitals inform victims of sexual assault about EC. ${ }^{3}$ We call such laws "ED-access laws." Finally, in 2006, the FDA allowed EC to be sold in pharmacies without a prescription to all women over the age of $18 .{ }^{4}$

This paper studies these expansions of access to EC. We study how such policies affected fertility and abortion rates. We also explore how the expansion of access to EC changed the venue in which women procure the medication, and the potential consequences of such a change.

Despite the convictions of many policy makers, the theoretical impact of EC on fertility and abortions is not obvious. We first present a simple model that explains the conditions under which easier access to EC will lower natality and abortions. The effect of EC is ambiguous, because easier access to EC, which mitigates a risk of sexual activity, may change women's behavior.

This paper then explores the impact that each of these policies has had on fertilityrelated outcomes. We first estimate the impact of state policies before the 2006 FDA policy change. We then estimate the impact of the FDA policy change by comparing outcomes in states that previously had EC-related legislation to those that did not. We find that pharmacy-access laws and ED-access laws had little effect on birth or abortion rates. The estimates, for instance, rule out decreases in overall fertility larger than 2 percent. We find similar results even amongst sub-populations that are less likely to use

\footnotetext{
${ }^{2}$ Most of these states required that the pharmacist enter a collaborative practice agreement with a physician, the others simply established a protocol. In the appendix, we distinguish between the two types of laws as a robustness check.

${ }^{3}$ The majority of these laws mandate that the hospital itself provide the medication. Two states, South Carolina and Ohio, passed EC-related legislation for assault victims, but failed to enforce it. We ignore this legislation in our empirical specifications, following the classification of the Guttmacher Insitute.

${ }^{4}$ In 2009, this availability was extended to all women older than age 17. Our data do not allow us to study this, more recent, policy change.
} 
regular contraceptives. Nonetheless, we demonstrate that sales of EC rose dramatically during this time period. This suggests that women who purchased EC following the policy change may have faced a small risk of pregnancy beforehand or that a behavioral response counteracted the increase in contraceptive power.

Our results stand in stark contrast to research on other forms of contraception. Bailey (2010) finds that greater availability of the contraceptive pill decreased marital fertility, while Kearney and Levine (2009) demonstrate that the price of oral contraceptives affects the teenage birth rate. ${ }^{5}$ Similarly, policies that have expanded access to abortion have had a significant impact on fertility and the composition of births (Ananat et al., 2009, 2007; Donohue and Levitt, 2001), while policies that mandate waiting periods for abortion may have decreased the abortion rate (Joyce and Kaestner, 2000).

Our results suggest more modest impacts of EC than two other existing studies that focus on increased access to EC in the general us population. ${ }^{6}$ Oza (2009) studies the change in outcomes after the FDA policy change. She relies on a database of private insurance claims and finds that the FDA policy change decreased the number of abortions. Zuppann (2010) studies how pharmacy-access laws affected birth rates before the FDA policy change. He finds that the state laws led to large decreases in birth rates. ${ }^{7}$

Our results, however, confirm findings from small-scale, randomized-controlled medical trials. Glasier and Baird (1998) offer one group of women a supply of EC to keep at home and require a second group to obtain EC through standard channels, only with a prescription. The authors find that the first group had fewer unintended pregnancies. The study, however, included only a small sample of subjects, selected because they had all previously used EC or had an abortion. In contrast, other studies find no effect of

\footnotetext{
${ }^{5}$ In addition, there exists some evidence that oral contraceptives changed the composition of births (Ananat and Hungerman, 2011).

${ }^{6}$ Another study by Durrance (2007) focuses on Washington state only, the first state to implement pharmacy access.

${ }^{7}$ To our knowledge, no other study has estimated the impact of ED-access laws so far.
} 
EC on fertility (Raymond et al., 2006; Raine et al., 2005). Raymond et al. (2007) review 23 studies of EC and conclude that randomized access to EC has not been shown to decrease unintended pregnancies. Glasier et al. (2004) find that the provision of emergency contraception does not change abortion rates either. ${ }^{8}$

Having found little evidence that easier access to EC has changed fertility-related outcomes, we then measure whether EC-related laws affect the venue in which women acquire the pill. To do so, we rely on a near census of ED visits for selected states. We find that the FDA ruling led to a large decrease in ED visits related to EC. This suggests that expansions of access to EC have affected the venue in which women acquire the medication and thereby lowered the total cost of distributing EC. We also find that, in the absence of pharmacy access laws, ED-access laws increase EC-related visits, indicating that guaranteed access to EC may play a role in determining whether women go to the ED.

While cost-saving, the shift to over-the-counter provision of EC may have led to unintended consequences. Sexual assaults may be one reason women seek EC at the ED. Hospital staff, unlike pharmacists, provide other services beyond EC provision, and such services may not be utilized if EC is accessed over-the-counter. In particular, we find suggestive evidence that expansions of access to EC led to a decrease in the number of sexual assaults reported to law enforcement. Such results must be interpreted cautiously; we rely on only one source of data on sexual assaults and find an impact only of pharmacy-access laws before the FDA ruling. Still, this finding is consistent with the fact that assault victims are likely to encounter less encouragement and opportunity to report the crime

\footnotetext{
${ }^{8} \mathrm{~A}$ related question is whether access to EC may encourage risky behavior. Previous research has found little evidence for this. Raine et al. (2000) find that women given an at-home supply of emergency contraception shifted to less effective methods of contraception. This result, however, has not been found by other, similarly conducted studies (Jackson et al., 2003). Gold et al. (2004) find no effect of EC on the use of other contraceptives. Meanwhile, Belzer et al. (2005) suggest that teenagers who are given advanced provision of EC are more likely to have unprotected sex, but the methodology involved has been criticized (Trussell et al., 2006).
} 
at a pharmacy than at an ED.

The paper proceeds as follows. Section 2 presents a theoretical framework that clarifies how access to EC ought to affect outcomes. Section 3 describes the data at our disposal and our empirical strategy. Section 4 then presents our empirical results; how access to EC affects births, abortions, ED visits, and reports of sexual assault. Section 5 concludes.

\section{Theoretical Framework}

This section explains how EC can affect fertility-related outcomes. EC is unlike traditional contraception in that it is intended for use after intercourse. Unlike abortion, however, EC must be taken before one knows whether intercourse has resulted in pregnancy. In this sense, EC lies between traditional contraception and abortion in a woman's decision tree. This section studies that decision tree with a simple model, inspired by the work of Levine and Staiger (2002) and Kane and Staiger (1996).

The model predicts how EC will affect the number of sexual encounters, pregnancies, abortions, and births. In general, the model suggests that the effect of EC on these outcomes is surprisingly ambiguous. The ambiguity stems from how EC can change exposure to pregnancy risk. Suppose, for instance, that women react to the introduction of EC by having more sexual encounters. That reaction alone increases the number of births, while the use of EC decreases the number of births. The net effect of EC on births and other outcomes is thus ambiguous. Below, we present this intuition more formally.

\subsection{Structure of the Model}

Suppose that women face a utility gain from intercourse, $S \in(0, \bar{S})$, and a utility gain from having a child, $B \in[\underline{B}, \bar{B}]$. If $B>0$, then a pregnancy is wanted, and if $B<0$, then a pregnancy is unwanted. These variables are randomly distributed in the population 
based on a density function $g(s, b)$. Abortion is available once a woman is pregnant at a utility cost, $A .^{9}$

Once pregnant, women compare the benefits of carrying the pregnancy to term to the cost of obtaining an abortion. They will choose abortion if $B<-A$. Thus, if a pregnancy occurs, a woman will receive a utility of $P \equiv \max \{B,-A\}$.

Suppose that, initially, the probability that a sexual encounter leads to pregnancy is q. Therefore, a woman will consent to sex if $S+q \cdot P>0$. The share of women who have sex is:

$$
\begin{aligned}
\gamma(q) \equiv & \int_{0}^{\bar{B}} \int_{0}^{\bar{S}} g(S, B) d S d B \\
& +\int_{\underline{B}}^{-A} \int_{q \cdot A}^{\bar{S}} g(S, B) d S d B+\int_{-A}^{0} \int_{-q \cdot B}^{\bar{S}} g(S, B) d S d B
\end{aligned}
$$

That is, the share of women who have sex is composed of those who want a baby (the first term in equation 1) and those who do not. The latter are composed of two groups: those who will pursue an abortion if pregnant (the second term in equation 1) and those who will not (the third term in equation 1). A woman can only become pregnant if she consents to sex, and thus the share of women who become pregnant is $\gamma(q) \cdot q$.

\subsection{The Effect of Emergency Contraception}

Suppose that EC is introduced, and that it lowers the probability of pregnancy from $q$ to $q^{\prime}$ at a cost of $c$. The parameter $q^{\prime}$ reflects not just the effectiveness of the technology, but also the probability that a woman obtains EC and uses it correctly.

After sexual intercourse, a woman must compare the benefits of taking EC with its cost. She will prefer taking EC if $S+q \cdot P<S+q^{\prime} \cdot P-c .^{10}$ Under these assumptions,

\footnotetext{
${ }^{9}$ These costs and benefits reflect not only the financial cost of abortion or pregnancy, but also stigma, opportunity cost, and psychic costs.

${ }^{10} \mathrm{We}$ assume that EC is less costly than abortion, and thus $-A<\frac{c}{q^{\prime}-q}$.
} 
EC will unambiguously raise the share of women who have sex, since some women with a previously negative total payoff to sex now face a positive payoff. ${ }^{11}$

The share of women who become pregnant, however, may rise or fall after the introduction of EC. Wanted pregnancies are unaffected by EC, because women for whom a baby is welfare-enhancing will not consume EC. Unwanted pregnancies, however, may increase or decrease. That ambiguity stems from two forces. On the one hand, the availability of EC leads more women to have sexual intercourse. On the other hand, pregnancy is now less likely to occur. The appendix demonstrates that unwanted pregnancies will decrease if the ability of EC to reduce pregnancies is large relative to the induced behavioral change.

The share of women who have an abortion may also rise or fall. There are two sources of uncertainty that cause individuals to use abortion (Levine and Staiger, 2002). First, some women decide to have sex based on a sufficiently high expected value of $B$, but are uncertain of the true value of $B$ until a pregnancy occurs. Such women are unlikely to use EC to replace abortion, because they do not gain additional information about $B$ from waiting until after intercourse. The second source of uncertainty is the stochastic nature of pregnancy itself. Abortion is a cost that is only realized if pregnancy occurs, whereas traditional contraception and EC must be used before knowing whether pregnancy will occur. No additional information is gained by waiting until intercourse occurs, but EC may act as insurance against pregnancy. The net effect of EC on abortion is ambiguous, and for the same reason that the effect of EC on pregnancies is ambiguous. On the one hand, EC induces more women to choose sexual intercourse. On the other hand, the probability that these women need an abortion falls, because they consume EC. Finally, combining the ambiguous effect of EC on pregnancies and abortions yields the prediction that EC may raise or lower the number of births.

The ambiguity of EC on these outcomes depends on the magnitude of $q^{\prime}$ relative

\footnotetext{
${ }^{11}$ The appendix presents a formal proof of both this prediction and the following predictions.
} 
to $q$. If, for instance, EC were to reduce the probability of pregnancy from $q$ to zero, then EC would unambiguously reduce the number of pregnancies, abortions, and births. EC, however, only reduces the probability of pregnancy by 75-95 percent (Trussell and Raymond, 2012). Over one year, a sexually active woman who uses EC as her only form of birth control faces a 20-40 percent risk of pregnancy. Consequently, we cannot rule out that the effect of EC on these outcomes is theoretically ambiguous. ${ }^{12}$

In this way, the model describes the introduction of EC and not expansions of access to EC. The model, however, leads to nearly identical predictions in either case. We clarify the difference between the introduction of EC and expansions of access in the theoretical appendix.

\subsection{Emergency Contraception versus Traditional Contraception}

This model does not explicitly capture the choice between traditional contraception and EC. Formally incorporating traditional contraception into the model would complicate the derivations, but would not provide additional insights. ${ }^{13}$ Instead, we discuss traditional contraception informally as follows.

Traditional contraception must be purchased before sexual intercourse. Women who are certain of the benefits of sex, $S$, will purchase traditional contraception rather than EC. ${ }^{14}$ For such women, EC provides no additional benefit. There also exist, however, women for whom the benefits of sex, $S$, are uncertain. For such women, EC offers an advantage over traditional contraception. When the benefits of sex, $S$, are uncertain but expected to be low, women may not wish to purchase traditional contraception. If $S$ is revealed to be very large, then such women can purchase EC after intercourse. Uncertainty

\footnotetext{
${ }^{12}$ Note that the introduction of EC unambiguously increases the welfare of women in this framework.

${ }^{13}$ Women would have to choose between traditional contraception and EC based on which one provided the highest protection at the lowest cost. If EC were relatively more expensive, no woman would use it and an expansion of access to EC would have no effect on outcomes. If, on the other hand, EC were relatively inexpensive, then some women would consume EC. Only in this case would EC affect outcomes.

${ }^{14} \mathrm{EC}$ is comparable in cost to one month of oral contraceptives.
} 
in $S$, or rather, uncertainty over future sexual encounters, thus drives demand for EC.

A second reason women may choose EC involves stochastic shocks to $q$. For example, if a condom breaks during intercourse, then the probability of pregnancy is suddenly higher than it had been before. The woman may then consume EC, as a result. In this way, EC can be used once additional information about $S$ and $q$ is revealed. ${ }^{15}$

Without such uncertainty, very few economic agents would consume EC. First, EC is relatively expensive. Second, EC cannot be used frequently, and provides little additional benefit if a primary method of contraception is already used properly. In this sense, the availability of EC will only affect women who face greater uncertainty over future sexual encounters. Women who face such uncertainty are more likely to be young, poorer and unmarried. For that reason, we stratify some of the empirical results below on age, minority, and marital status.

\subsection{Victims of Sexual Assault}

EC may also be used in cases of sexual assault. In the context of the model, such women are those for whom $S+q \cdot P$ is negative, and yet they are forced to have sex. For such women, EC does not induce a behavioral response; the rate of sexual assaults is likely unaffected by the availability of EC. ${ }^{16}$ Thus, in contrast to the ambiguous results above, EC has an unambiguous effect on victims of sexual assault. For victims of sexual assault, the availability of EC reduces the number of births and abortions. ${ }^{17}$ We are aware of no studies that assess the effect of contraception access on victims of sexual assault. We believe that this represents a fruitful avenue for future research.

\footnotetext{
${ }^{15}$ Abortion is available once $q$ has been realized and potentially, once additional information regarding $B$ has been revealed.

${ }^{16}$ Furthermore, given the low probability of assault, women are unlikely to insure against assault by using traditional contraceptives and thus face a high $q$ if they are not using contraceptives for another reason.

${ }^{17}$ Victims of assault, however, compose a small share of the total population. It is thus difficult to estimate the effect of EC on outcomes for that population alone.
} 
We will also test empirically how the availability of EC affects the reporting of sexual assaults. When a sexual assault is reported to law enforcement, the victim provides a public good while bearing a private cost. She provides authorities with the identity of the perpetrator and thus lowers the probability that the perpetrator commits another assault. As in the case of other public goods, reporting of assaults may be under-provided. ${ }^{18}$ We present below suggestive evidence that access to EC in pharmacies reduces the share of assaults that are reported to law enforcement. This suggests that when the private benefit to reporting is diminished, fewer assaults are reported. In that sense, wider access to EC decreases the private costs borne by victims, but may also decrease the provision of a public good. We discuss this implication further below.

\section{Data and Empirical Strategy}

We measure the effect of EC with a simple, difference-in-difference framework. Specifically, we first evaluate the state laws that expanded access, and then test how states that passed such laws were differentially affected by the FDA policy change.

Table 1 presents the dates when EC-related laws were passed. ${ }^{19}$ Between 1997 and 2006, 9 states passed pharmacy-access laws and 10 states passed ED-access laws. An additional 6 states, and the District of Columbia, passed ED-access laws after the FDA policy change made EC available at pharmacies. ${ }^{20}$ The states that passed EC-related legislation may be systematically different from states that did not. Still, all of our empirical results control for fixed differences between the states. Moreover, we test for time-varying differences between states by including linear time trends in our regressions

\footnotetext{
${ }^{18}$ After an assault, the victim may also be tested for sexually-transmitted infections. This may involve an additional positive externality.

${ }^{19}$ For the results below, we adjust the relevant date that each law was passed based on the outcome. For visits to the ED, we use the actual date. For abortions, we add 60 days to the law's passage, to account for the average gestation at abortion. For births, we add 266 days.

${ }^{20}$ Note that both types of state laws did not restrict the age at which women could obtain EC, whereas the FDA ruling made EC available only to women older than 18 .
} 
and by exploring event-study specifications. ${ }^{21}$

The FDA policy change was announced on August 24, 2006. However, unlike the state laws, the FDA policy required suppliers to produce a new, over-the-counter version of EC. Suppliers shipped that version in November of 2006, roughly three months after the FDA policy change. We thus consider the effective date of the FDA policy change to be November of 2006.

For the state laws, we estimate a regression of the form:

$$
y_{s t}=\beta \cdot I\left\{\text { EC State } \operatorname{Law}_{s t}\right\}+\gamma \cdot X_{s t}+\alpha_{s}+\alpha_{t}+\alpha_{s} \cdot t+\varepsilon_{s t},
$$

where $y_{s t}$ is an outcome in state $s$ at time $t$ and $I$ EC State $\left.\operatorname{Law}_{s t}\right\}$ is equal to 1 when the state has such a law in place. ${ }^{22}$ The regression allows each outcome to evolve along a separate linear time-trend and to differ permanently by state. We also include a variety of time-varying controls in each regression: the state unemployment rate, its poverty rate, welfare benefits for a family of four, the AFDC/TANF benefit level, and the availability of subsidized contraception through Medicare as compiled by Kearney and Levine (2009). ${ }^{23}$ We adjust the standard errors to allow for auto-correlation between observations from the same state. ${ }^{24}$ This framework requires one key assumption: that, in the absence of the policy changes, the path of the outcomes in each state would have differed only by a linear trend. We test the validity of that assumption below using more flexible event-study specifications.

\footnotetext{
${ }^{21} \mathrm{~A}$ table without state-specific time trends is included in the appendix.

${ }^{22}$ For annual data, we code a law as having been implemented if the law (or its expected consequence) was in place for more than 183 days of the year. For monthly data, we require that the law or its consequences be in place for more than 14 days of the month.

${ }^{23}$ The information on welfare comes from the University of Kentucky Poverty Research Center database (2011) and from Bitler et al. (2006).

${ }^{24}$ For these regressions, we restrict our sample to the years before the FDA policy change, since we expect that states with such laws in place would be affected very differently by the FDA ruling. Specifically, for outcomes in which we expect an immediate change in behavior, we only look at years before (and including) 2005, while for births, where we expect the outcome to be delayed by a year, we only restrict our sample to years before (and including) 2006.
} 
To evaluate the 2006 FDA policy change, we estimate a similar regression in which states that had already passed a pharmacy-access law are the control group. We only use the latest period of the data (2004-2008) for that estimation since many of the control states changed their laws during the previous period. ${ }^{25}$ Although the FDA policy was not a substitute for ED-access laws, it may have obviated such laws; thus, we also compare the impact of the FDA policy on states that previously had ED-access laws in place.

We have compiled outcomes from a variety of sources. We observe the number of births per month in each state from a census of births collected by the National Vital Statistics System. ${ }^{26}$ For abortion rates, we rely on state-by-year estimates of the number of abortions calculated by the Centers for Disease Control and Prevention. ${ }^{27}$. We have also compiled data on sexual assaults reported to authorities via the Federal Bureau of Investigation (FBI) Uniform Crime Report. ${ }^{28}$

Finally, we have compiled a large database of ED visits by month and year based on data from the Healthcare Cost and Utilization Project (HCUP). Our sample includes a near census of ED visits from Arizona (2005-2008), California (2005-2008), Iowa (20042007), New Jersey (2005-2008), and Wisconsin (2004-2008). ${ }^{29}$ Of these five states, New Jersey, Wisconsin, and California passed ED-access laws. ${ }^{30}$ We construct aggregate counts of all ED visits by month for these states, and isolate ED visits in which the patient received

\footnotetext{
${ }^{25}$ In such regressions, we exclude any state that changed its policies such that it would have affected the outcomes of interest in 2006.

${ }^{26}$ We stratify births by the age of the mother. We have also stratified births based on the marital status and race of the mother. The results are extremely similar to the ones presented below.

${ }^{27}$ These abortion data rely on states themselves reporting the relevant statistics, unlike the survey data compiled by the Alan Guttmacher Institute. The latter, however, are not available on an annual basis by state. We have data on 48 states in our sample.

${ }^{28}$ The crime data exist at the state-year level. Some states make available monthly crime data, but too little such data exist to precisely estimate the regression above at the monthly level.

${ }^{29}$ The administrative data cover all hospitals regulated by the state. Thus, for instance, we do not observe ED visits at Veteran Administration hospitals. Such visits are likely a very small share of all visits related to EC.

${ }^{30}$ California also passed a pharmacy-access law. Both California laws were implemented before the HCUP sample period, which prevents us from measuring their impact.
} 
EC or in which the patient was listed as a sexual assault victim. ${ }^{31}$

\section{Results}

This section presents our empirical results. We first discuss the effect of access to EC on births and abortions, outcomes on which most of the public debate and previous literature has focused. As our model indicates, however, the effect of EC on such outcomes is theoretically ambiguous. We then describe how access to EC affects visits to hospitals and reports of sexual assault, outcomes for which the model suggests we are more likely to observe an impact.

\subsection{Births and Abortions}

Table 2 presents a series of difference-in-difference estimates that test for the effect of access to EC on natality. The regressions include state-specific linear time trends and time-varying control variables. ${ }^{32}$ We focus on four different measures of natality: total births, total births for women under the age of 18, total births for women aged 18-30, and total births for women older than 30. The first panel restricts the sample to 1995-2006, before the FDA policy change. The second panel presents estimates based on 2004-2008, in which states with pharmacy-access laws compose the control group for the FDA policy change. ${ }^{33}$

Panel A of Table 2 suggests little relationship between natality and ED-access laws; all point estimates are extremely small, although the confidence intervals only rule out

\footnotetext{
${ }^{31}$ EC-related visits have International Classification of Diseases $9^{\text {th }}$ Revision (ICD-9) code "V2503," and assault-related visits have ICD-9 code "V715."

${ }^{32}$ As described above, these time-varying control variables include the state unemployment rate, its poverty rate, welfare benefits for a family of four, the AFDC/TANF benefit level, and the availability of subsidized contraception through Medicare as compiled by Kearney and Levine (2009).

${ }^{33}$ The table presents regressions that include controls for both types of state laws simultaneously. We obtained similar results when evaluating each law separately.
} 
decreases in overall natality of roughly 2 percent. ${ }^{34}$ Additionally, Panel A presents no evidence that pharmacy-access laws lowered births in each state. In contrast, the results suggest a 2.2 percent increase in births after states pass a pharmacy-access law (for women aged 18-30). That increase in births is surprisingly statistically significant. To test whether this increase is a true effect of the legislation, we run event-study regressions, which estimate the effect of pharmacy-access laws in each year before and after their passage. Figure 1 presents the results of that regression. The figure suggests that pharmacy-access laws did not have a discontinuous effect on natality. Natality in states that passed pharmacy-access laws was on an increasing (non-linear) trend before passage of the laws. This suggests that the results in panel A of Table 2 are misleading. ${ }^{35}$

Furthermore, if the results of panel A were taken at face value, they would imply an unusual response to pharmacy-access laws. As described by our model, access to EC will increase the birth rate when the behavioral response to the drug is substantially larger than the birth-prevention effect of the drug. The point estimates seem unusually large given that less than 5 percent of women say that they have used EC in the last year. Those women who have used EC used it less than twice on average (Zuppann, 2010). Any increase in births would need to be driven by women changing their behavior based on availability of the drug, but becoming pregnant nonetheless.

Finally, the bottom panel of Table 2 suggests little effect of the FDA policy change on natality. For 18-30 year-olds, states with no pharmacy-access law experienced a statistically insignificant 1.8 percent decrease in natality after EC was available over-the-counter. Such estimates can reject a negative impact of the FDA policy change on births larger

\footnotetext{
${ }^{34}$ The regressions in Table 2 are demanding of the data; they include many controls. We find, however, qualitatively similar estimates when we exclude state-specific linear time trends and state-specific timevarying control variables. Such results are presented in Appendix Table 1.

${ }^{35}$ The results of Table 2 do not match the findings of Zuppann (2010). Our approach differs from that of Zuppann (2010) in several ways. We analyze natality at the monthly level in log form, whereas he focuses on annual birth rates. We also focus on a narrower range of years to study. Finally, we rely on a slightly different set of dates for each pharmacy-access law.
} 
than 4 percent.

Potentially, we may not estimate a statistically significant effect here because the utilization and impact of EC is too low in the general population. We have conducted the analysis for many sub-populations (race, marital status, number of previous pregnancies, and so on) and have still found no impact. For instance, Table 3 presents estimates of our preferred specification solely for births by black, unmarried women. ${ }^{36}$ We focus on this population, because it is the group least likely to be using traditional contraceptives, and thus at highest risk of unintended pregnancy without access to EC. Table 3 presents no evidence that natality fell for that population after the policies of interest.

Table 4 presents a similar set of estimates to Table 2, but with abortions by state and year as the outcome of interest. As a whole, the table suggests no effect of EC-related laws on abortion. No point estimates are statistically significant at conventional levels, but the confidence intervals are wide. For instance, the results only rule out a reduction in abortions among women aged 20-29 of more than 12 percent after ED-access laws. The estimated impact of pharmacy-access laws is positive for most age groups, but statistically insignificant. The results do not reject reductions of less than 7 percent.

In summary, neither Table 2 nor Table 4 present significant evidence that EC-related legislation affected births or abortions. ${ }^{37}$ This confirms the results of medical studies, but care should be taken in interpreting these results.

First, one may wonder whether the legislation had little effect because it did not actually increase the consumption of EC. (This would be akin to a weak first stage in an instrumental variable setting.) We investigate this possibility with sales records from

\footnotetext{
${ }^{36}$ Information on educational attainment exists only for certain states and certain years, thus the number of observations falls across columns in Table 3.

${ }^{37} \mathrm{We}$ also explored whether birth and abortion rates of 18- versus 17 -year-olds changed differently around the FDA ruling, given the differential treatment of ages under the policy. To do so, we used natality and abortion records from the state of Texas. We found no evidence of such a pattern. Moreover, we used the natality records to explore whether there was any change in women's attributes around the FDA ruling and were unable to obtain any significant results as well.
} 
Barr Pharmaceuticals, the primary producer of EC. Unfortunately, the sales data are not available at the state-year level. Nevertheless, we directly observe the impact of the FDA policy change on national sales of EC. Figure 2 plots the total sales of Plan B from 2006 through 2009. The figure demonstrates the rapid decline of prescription sales for EC following the August, 2006 FDA policy change. The policy change also led to a rapid increase in over-the-counter sales, as Barr Pharmaceuticals released the newly packaged product for over-the-counter sale. From 2006 to 2007, Plan B sales more than doubled, increasing by $\$ 47$ million, with unit sales going from approximately 16,000 sales per week to over 34,000 in 2007. Sales continued a steady climb, doubling again between 2007 and 2009. This large increase in Plan B sales is evidence of the direct effect of the FDA policy change. We are thus skeptical that the lack of a pattern in Table 2 and Table 4 is driven by lack of variation in sales of the pill. Furthermore Kavanaugh et al. (2011) argue that pharmacy-access of EC is responsible for doubling the number of women who have ever used EC from 4 percent in 2002 to nearly 10 percent in 2008.

A second possibility is that we may simply be unable to detect significant effects of the EC-related legislation because of the way EC operates. EC only prevents pregnancy from a single sexual encounter, so it eliminates a risk of pregnancy of only $3-5$ percent, the risk of pregnancy from a single, unprotected sexual encounter. If, however, women use EC because they believe themselves to be at a greater risk of pregnancy, then women taking EC may face a 10 percent pregnancy risk, the approximate peak at pregnancy during the menstrual cycle (Wilcox et al., 2001). ${ }^{38}$ In that case, if EC lowers this pregnancy risk by 75 percent, then women taking EC would experience a 7.5 percentage-point reduction in pregnancy risk. ${ }^{39}$ If the FDA policy change caused roughly one-million additional pills to

\footnotetext{
${ }^{38}$ The risk of pregnancy from a single, unprotected sexual encounter reaches 29 percent on the day before ovulation, but due to ovulation occurring irregularly within the menstrual cycle, a woman is unlikely to pinpoint this peak risk.

${ }^{39}$ Clinical trials show EC to be up to 89 percent effective, but this effectiveness decreases with the time between intercourse and consumption of the pill.
} 
be consumed in its first year, then there would be 75,000 averted pregnancies, slightly less than 2 percent of all births. The regressions above cannot rule out such a change.

Alternatively, women who take EC may be at a decreased risk of pregnancy. For instance, women who take EC may do so principally because another method of contraception has failed. Some studies indicate that this is indeed the case (Trussell et al., 2004). If women who consume EC face a lower risk of pregnancy from a single sexual encounter than average, say 2 percent, then one million additional pills would prevent 15,000 unintended pregnancies, a negligible amount relative to total births.

Under either scenario, very large changes to births or abortions are unlikely, given that each additional pill prevents pregnancy from only a single sexual encounter. More broadly, unexpected sexual encounters may account for a small percentage of overall pregnancies. Roughly half of women seeking abortions had been using some form of contraception, and few report unexpected sex as a factor in their abortion (Jones et al., 2002). If individuals who use EC actually face a low risk of unintended pregnancy, and individuals most likely to experience unintended pregnancy are unlikely to seek EC, then the impact of expanded access will be greatly diminished. We conclude that policies offering over-the-counter access to EC avert a private cost in acquiring the pill through a physician, but do not avert the social cost of unintended pregnancy.

\subsection{ED Visits}

Despite the estimated null effect on birth and abortion rates above, state and federal legislation may have changed the way women acquire EC. To test for that possibility, Figure 3 presents monthly counts of EC-related visits to emergency departments. The vertical line indicates the date when the FDA allowed all women to obtain EC in pharmacies without a prescription. ${ }^{40}$ The figure shows a clear decrease in EC-related visits after the

\footnotetext{
${ }^{40}$ We restrict the sample to visits by women older than age 18 . Only such women would have been affected by the legislative change. No drop is observed for EC-related visits by women younger than 18 .
} 
FDA ruling. EC-related visits decrease from roughly 250 each month to roughly 150 each month. In contrast, the number of other visits seems to rise. Though a relatively small share of ED visits are related to EC, Figure 3 suggests that such visits became less common after women could obtain EC in pharmacies. Given that our five states capture about 20 percent of the population in the United States, this would suggest that the FDA policy change led to a decrease of about 500 visits per month to ED's.

In contrast to the pharmacy-access policies, we would expect ED-access laws to increase visits to the ED to obtain the pill, as its provision would be guaranteed. ED data do not exist that would allow us to estimate how each ED-access law affected the number of ED visits. Nevertheless, we have obtained records of ED visits for New Jersey, which passed such a law in April of 2005. Figure 4 presents ED visits in New Jersey before and after the state passed its ED-access law. The figure suggests that EC-related ED visits were decreasing before the law was passed and then increased dramatically immediately after the law was passed. In contrast, other ED visits experienced a secular increase before and after the law. The magnitude of the change suggests an increase of about 25 visits per month. Given that the population of New Jersey is about 3 percent of that of the United States, that increase is slightly larger than the decrease that was experienced after the FDA ruling. By contrast, no such pattern is observed in Wisconsin, which passed its ED-access law after the FDA policy change. This implies women did not increase their visits to the ED for EC in response to guaranteed access when a lower cost route, pharmacy access, is already available.

As a whole, these figures suggest that expansions of access to EC substantially changed the venue in which women procured the medication. Given the expense of ED visits (Bamezai et al., 2005), the figures suggest that such laws affect the total cost of distributing EC. These costs are both monetary as well as related to the time and stress associated with visiting the ED. However, patients in an ED are given access to a wider array of 
staff and services than customers in a pharmacy. Potentially, that difference may lead to changes in outcomes. We test for such changes next.

\subsection{Reports of Sexual Assault and EC}

We next test whether expansions in access to EC affect reports of sexual assault. A priori, one might expect such an effect. In our model, victims of sexual assault are those for whom the impact of EC would be the largest. Furthermore, as demonstrated above, both state pharmacy-access laws and the FDA policy change enabled women to procure EC in pharmacies rather than hospitals. In either a pharmacy or an emergency department, it is the victim's decision as to whether a sexual assault is reported to the police. Hospital staff, however, may be more effective at encouraging women to report such crimes.

Table 5 presents the results of difference-in-difference regressions with reported sexual assaults as the outcome of interest. The second row of Panel A suggests that pharmacyaccess laws did indeed reduce reported sexual assaults. In particular, states experienced a significant 9 percent decrease in reported assaults after they passed pharmacy-access laws. This implies a decrease of 0.31 reported assaults per 10,000 people (compared to an average of 3.5 assaults per 10,000 people). While this effect is not large, it is consistent with the decreased number of visits to the ED (6,000 annually).

To check that this result is not spurious, Figure 5 presents the point estimates from an event-study specification that evaluates the effect of state ED-access laws on reports of sexual assault. None of the 95-percent-level confidence intervals in Figure 5 exclude zero. We find this unsurprising; an event-study specification is demanding, given that these data only exist at the state-year level. Still, we find the figure suggestive. The point estimates suggest that assaults dropped for all post-law periods and did so exactly the year that the pharmacy-access laws were passed. While that drop is not statistically significant at conventional levels, the point estimates do not form a linear trend, but 
rather a step function.

In addition, Table 5 suggests that ED-access laws increased the reporting of sexual assaults. Perhaps such laws increased the number of women choosing to go to the ED following a sexual assault. Those point estimates are only statistically significant at the 10-15 percent level. Nevertheless, the finding is consistent with the role that ED access has in guaranteeing care for prevention of pregnancy to assault victims. This further suggests that women who seek EC in hospitals are likely to report sexual assault.

Columns 3 and 4 of Table 5 report the results of a falsification check. We estimate similar regressions in which the number of aggravated assaults reported to the FBI is the dependent variable. Aggravated assaults are non-sexual in nature, and the reporting of such crimes should not be related to the availability of EC. Reassuringly, columns 3 and 4 suggest that EC-related legislation had no effect on aggravated assault. ${ }^{41}$ Panel B of Table 5 presents similar estimates for the FDA policy change. We find no evidence of a change in the report of sexual assaults after the national policy change.

Finally, we examine the impact of the FDA policy change on the nature of ED visits. Specifically, we test whether the FDA policy change affected ED visits for sexual assaults in our HCUP sample. Figure 6 presents the number of such visits over time. ${ }^{42}$ The number of sexual-assault-related visits fell dramatically around the time of the FDA ruling. In contrast, ED visits for other conditions remained on the same trend. Although visits for sexual assault became more common in the summer of 2007, the relative number of such visits remained below trend. ${ }^{43}$ The effect of the FDA policy change is also clear, however, if we control for month-of-year fixed effects. The magnitude of this change is substantial; assault-related visits decreased by about 100 visits per month in our five-state sample.

Overall, this evidence is suggestive. It implies that pharmacy access to EC may have

\footnotetext{
${ }^{41}$ Reports of robbery are similarly unaffected.

${ }^{42}$ Only visits by women older than 18 are in the sample.

${ }^{43}$ Visits related to sexual assault are subject to a seasonal pattern, occurring more frequently in the summer than in the winter.
} 
led to a decrease in reported sexual assaults. The welfare implications of this finding are unclear. Easier access to EC means lower transaction costs for victims of sexual assault. However, it may also limit the other services provided to sexual assault victims, and hinder the apprehension of perpetrators. More research is needed in this area, to confirm how access affects assault reporting, and what policy steps could be taken to mitigate the unintended consequences of increased access.

\section{Conclusions}

In summary, this paper studies the effects of access to EC. We first present a theoretical framework that suggests that the net effect of EC is ambiguous. On the one hand, there exists a direct effect - the consumption of EC prevents pregnancies. On the other hand, there exists an indirect effect; EC may induce a behavioral response which leads to more sexual encounters, and hence, more pregnancies. Finally, the likely impact of EC depends on when additional information on uncertain variables is revealed to the woman: information revealed near the time of intercourse (such as a broken condom) is related to EC use, while information that is gained long before or long after intercourse will make EC less useful relative to traditional contraception or abortion. Our model also suggests that the use of EC relative to traditional contraceptives and abortion will depend on the timing of information updates on the costs and benefits of unprotected sex and pregnancy.

Consistent with this model, we find no empirical evidence that expanded access to EC has decreased birth rates or abortions, even for at-risk populations. We caution that the associated confidence intervals are relatively wide, and that more research is needed to recover precise estimates. Still, we do not observe large changes in natality or abortion, as some opponents of EC have feared, nor do we find large decreases in unintended pregnancy, as some proponents had hoped. We find that wider access to EC increases utilization of 
EC, thus we do not believe that a lack of variation in the actual consumption of EC is driving our results. EC may mostly affect women for whom the chance of pregnancy is low, and thus it would be impossible to observe very large decreases in response to such policies.

These results clarify the dynamics of unintended pregnancies. The likely impact of EC depends on when additional information on uncertain variables is revealed to the woman: information revealed near the time of intercourse (such as a broken condom) encourages EC use, while information that is gained long before or long after intercourse will make EC less useful relative to traditional contraception or abortion. Our results imply that few unintended pregnancies are anticipated immediately after intercourse, indicating that uncertainty around the time of intercourse may not be a major driver of unintended pregnancy. Long term decisions may play a larger role in determining risk for unintended pregnancy, and the women facing the greatest risk of such pregnancies may not be the users of EC. Sexual assault victims represent an exception, given that they face a large unanticipated shock that EC can be used to mitigate.

Our results do suggest that expanded access to EC has changed the venue in which women obtain EC, encouraging women to visit EDs when access there is guaranteed, and then switch from EDs to pharmacies when the drug is available OTC. Visits to pharmacies are less expensive than visits to emergency departments. Thus, if nothing else, expansions in access to EC have lowered the total cost of distributing the drug.

This lower cost, however, appears to have brought a potential unintended consequence: access to EC in pharmacies may reduce the reporting of sexual assault. To mitigate this impact, new policies may be necessary to encourage crime reporting by sexual assault victims that visit pharmacies. Further evidence is needed on this, but such a possibility was not, to our knowledge, discussed in the debate over EC, and deserves greater attention. 


\section{References}

Ananat, E. and D. Hungerman (2011). The power of the pill for the next generation: Oral contraceptions effects on fertility, abortion, and maternal and child characteristics. Review of Economics and Statistics (forthcoming).

Ananat, E. O., J. Gruber, and P. Levine (2007). Abortion legalization and life-cycle fertility. Journal of Human Resources 42(2), 375-397.

Ananat, E. O., J. Gruber, P. B. Levine, and D. Staiger (2009, November). Abortion and selection. The Review of Economics and Statistics 91(1), 124-136.

Bailey, M. J. (2006, 02). More power to the pill: The impact of contraceptive freedom on women's life cycle labor supply. The Quarterly Journal of Economics 121(1), 289-320.

Bailey, M. J. (2010, March). "momma's got the pill": How anthony comstock and griswold v. connecticut shaped us childbearing. American Economic Review 100(1), 98-129.

Bamezai, A., G. Melnick, and A. Nawathe (2005, May). The cost of an emergency department visit and its relationship to emergency department volume. Annals of Emergency Medicine 45, 483-490.

Belzer, M. ., K. . Sanchez, J. . Olson, A. . Jacobs, and D. . Tucker (2005). Advance supply of emergency contraception: A randomized trial in adolescent mothers. Journal of Pediatric and Adolescent Gynecology 18(5), 347-354.

Bitler, M. P., J. B. Gelbach, and H. W. Hoynes (2006, September). What mean impacts miss: Distributional effects of welfare reform experiments. American Economic Review 96(4), 988-1012.

Donohue, J. J. and S. D. Levitt (2001, May). The impact of legalized abortion on crime. The Quarterly Journal of Economics 116(2), 379-420.

Durrance, C. P. (2007, October). The effects of increased access to the morning-after pill on abortion and std rates. University of North Carolina Working Paper.

Ellertson, C. (1996, January). History and efficacy of emergency contraception: beyond coca-cola. International Family Planning Perspectives 28(2), 44-8.

Glasier, A. and D. Baird (1998). The effects of self-administering emergency contraception. The New England Journal of Medecine 339(1), 1-4.

Glasier, A., K. Fairhurst, S. Wyke, S. Ziebland, P. Seaman, J. Walker, and F. Lakha (2004). Advanced provision of emergency contraception does not reduce abortion rates. Contraception 69(5), 361-366. 
Gold, M. A., J. E. Wolford, K. A. Smith, and A. M. Parker (2004). The effects of advance provision of emergency contraception on adolescent women"s sexual and contraceptive behaviors. Journal of Pediatric and Adolescent Gynecology 17(2), 87-96.

Goldin, C. and L. F. Katz (2002, August). The power of the pill: Oral contraceptives and women's career and marriage decisions. Journal of Political Economy 110(4), 730-770.

Jackson, R. A., E. B. Schwarz, L. Freedman, and P. Darney (2003). Advance supply of emergency contraception: Effect on use and usual contraception-a randomized trial. Obstetrics and Gynecology 102, 8-16.

Jones, R. K., J. E. Darroch, and S. K. Henshaw (2002, November/December). Contraceptive use among us women having abortions in 2000-2001. Perspectives on Sexual and Reproductive Health 34(6), 294-303.

Joyce, T. and R. Kaestner (2000, January). The impact of mississippi's mandatory delay law on the timing of abortion. Family Planning Perspectives 32(1), 4-13.

Kane, T. J. and D. Staiger (1996, May). Teen motherhood and abortion access. The Quarterly Journal of Economics 111(2), 467-506.

Kavanaugh, M. L., S. L. Williams, and E. B. Schwarz (2011). Emergency contraception use and counseling after changes in United States prescription status. Fertility and Sterility 95(8), 2578-2581.

Kearney, M. S. and P. B. Levine (2009, October). Subsidized contraception, fertility, and sexual behavior. The Review of Economics and Statistics 91(1), 137-151.

Levine, P. B. and D. Staiger (2002, February). Abortion as insurance. NBER Working Papers 8813, National Bureau of Economic Research, Inc.

of Kentucky Center for Poverty Research, U. (2011). State-level data of economic, political, and transfer-program information for 1980-2010. Technical report. available at http://www.ukcpr.org/EconomicData/UKCPR_National_Data_Set_12_14_11.xlsx.

Oza, A. (2009, October). Plan b as insurance: The effect of over-the-counter emergency contraception on pregnancy terminations and stis. Unpublished Working Paper available at http://liberalarts.iupui.edu/economics/uploads/docs/oza.pdf.

Raine, T., C. Harper, K. Leon, and P. Darney (2000). Emergency contraception: Advance provision in a young, high-risk clinic population. Obstetrics and Gynecology 96, 1-7.

Raine, T. R., C. C. Harper, C. H. Rocca, R. Fischer, N. Padian, J. D. Klausner, and P. D. Darney (2005). Direct access to emergency contraception through pharmacies and effect on unintended pregnancy and stis. Journal of the American Medical Association 293, $54-62$. 
Raymond, E., J. Trussell, and C. Polis (2007, January). Population effect of increased access to emergency contraceptive pills: a systematic review. Obstetrics \& Gynecology $109(1), 181-188$.

Raymond, E. G., F. Stewart, M. Weaver, C. Monteith, and B. Van Der Pol (2006). Impact of increased access to emergency contraceptive pills: A randomized controlled trial. Obstetrics and Gynecology 108, 1098-1106.

Trussell, J. ., E. . Raymond, and F. . Stewart (2006). Letter to the editor. Journal of Pediatric and Adolescent Gynecology 19(3), 251.

Trussell, J., C. Ellerston, F. Stewart, E. G. Raymond, and T. Shochet (2004, April). The role of emergency contraception. American Journal of Obstetrics and Gynecology 190(4), 30-38.

Trussell, J. and E. G. Raymond (2012). Emergency contraception: A last chance to prevent unintended pregnancy.

Trussell, J. and F. Stewart (2000, November). Prevention of pregnancy resulting from rape: A neglected preventive health measure. American journal of preventive medicine 19(4), 228-229.

Wilcox, A. J., D. B. Dunson, C. R. Weinberg, J. Trussell, , and D. D. Baird (2001, April). Likelihood of conception with a single act of intercourse: providing benchmark rates for assessment of post-coital contraceptives. 63(4), 211-215.

Zuppann, C. A. (2010, November). Contraceptions role in dating and marriage. Unpublished manuscript available at http://home.uchicago.edu/ zuppann/Home/Home_ files/zuppann_jmp.pdf. 


\section{A Appendix}

Before EC, the share of women who have an unwanted pregnancy is:

$$
q \cdot\left(\int_{\underline{B}}^{-A} \int_{q \cdot A}^{\bar{S}} g(S, B) d S d B+\int_{-A}^{0} \int_{-q \cdot B}^{\bar{S}} g(S, B) d S d B\right) .
$$

The fraction of women who have an abortion before EC is introduced is:

$$
q \cdot \int_{\underline{B}}^{-A} \int_{q \cdot A}^{\bar{S}} g(S, B) d S d B .
$$

After EC is available, the model described in section 2 makes four predictions. First, it predicts that the share of women who have sex will unambiguously rise. The share of women who have sex after the introduction of $\mathrm{EC}$ is:

$$
\begin{aligned}
\int_{\underline{B}}^{-A} & \int_{c-q^{\prime} \cdot A}^{\bar{S}} g(S, B) d S d B+\int_{-A}^{\overline{q^{\prime}-q}} \int_{c-q^{\prime} \cdot B}^{\bar{S}} g(S, B) d S d B \\
& +\int_{\frac{c}{q^{\prime}-q}}^{0} \int_{-q \cdot B}^{\bar{S}} g(S, B) d S d B+\int_{0}^{\bar{B}} \int_{0}^{\bar{S}} g(S, B) d S d B .
\end{aligned}
$$

This share is unambiguously larger than the share before EC, $\gamma(q)$.

Note also that as $c$ increases, the share of women having sex decreases, because the derivative is given by:

$$
\begin{array}{r}
-\int_{\underline{B}}^{-A} g\left(c-q^{\prime} \cdot A, B\right) d B-\int_{-A}^{\frac{c}{q^{\prime}-q}} g\left(c-q^{\prime} \cdot B, B\right) d B \\
+\frac{1}{q^{\prime}-q}\left(\int_{-\frac{c q}{q^{\prime}-q}}^{S} g\left(S, \frac{c}{q^{\prime}-q}\right) d S-\int_{-\frac{c q}{q^{\prime}-q}}^{\bar{S}} g\left(S, \frac{c}{q^{\prime}-q}\right) d S\right)= \\
-\int_{\underline{B}}^{-A} g\left(c-q^{\prime} \cdot A, B\right) d B-\int_{-A}^{\frac{c}{q^{\prime}-q}} g\left(c-q^{\prime} \cdot B, B\right) d B<0 .
\end{array}
$$

Second, the model predicts that the share of women who become pregnant after EC 
may rise or fall. The share of women who become pregnant once EC is available is:

$$
\begin{array}{r}
q \cdot\left(\int_{\frac{c}{q^{\prime}-q}}^{0} \int_{-q \cdot B}^{\bar{S}} g(S, B) d S d B+\int_{0}^{\bar{B}} \int_{0}^{\bar{S}} g(S, B) d S d B\right)+ \\
q^{\prime} \cdot\left(\int_{\underline{B}}^{-A} \int_{c+q^{\prime} \cdot A}^{\bar{S}} g(S, B) d S d B+\int_{-A}^{\frac{c}{q^{\prime}-q}} \int_{c-q^{\prime} \cdot B}^{\bar{S}} g(S, B) d S d B\right) .
\end{array}
$$

For this number to be lower than the number of pregnancies before EC, EC must lower the number of unwanted pregnancies. (EC has no effect on the number of wanted pregnancies.) The number of unwanted pregnancies will fall only if:

$$
\frac{q^{\prime}}{q}<\frac{\int_{\underline{B}}^{-A} \int_{q A}^{\bar{S}} g(S, B) d S d B+\int_{-A}^{\frac{c}{q^{\prime}-q}} \int_{-q B}^{\bar{S}} g(S, B) d S d B}{\int_{\underline{B}}^{-A} \int_{c+q^{\prime} A}^{\bar{S}} g(S, B) d S d B+\int_{-A}^{\overline{q^{\prime}-q}} \int_{c-q^{\prime} B}^{\bar{S}} g(S, B) d S d B}<1,
$$

that is, only if the effectiveness of EC surpasses the number of added sexual encounters it generates.

When the price of EC rises, the impact on pregnancies is given by the following expression:

$$
\begin{array}{r}
-q^{\prime} \cdot\left(\int_{\underline{B}}^{-A} g\left(c+q^{\prime} \cdot A, B\right) d B+\int_{-A}^{\overline{q^{\prime}-q}} g\left(c-q^{\prime} \cdot B, B\right) d B\right) \\
\frac{1}{q^{\prime}-q} \cdot\left(-q \int_{-\frac{c q}{q^{\prime}-q}}^{\bar{S}} g\left(S, \frac{c}{q^{\prime}-q}\right) d S+q^{\prime} \int_{-\frac{c q}{q^{\prime}-q}}^{\bar{S}} g\left(S, \frac{c}{q^{\prime}-q}\right) d S\right)= \\
-q^{\prime} \cdot\left(\int_{\underline{B}}^{-A} g\left(c+q^{\prime} \cdot A, B\right) d B+\int_{-A}^{\frac{c}{q^{\prime}-q}} g\left(c-q^{\prime} \cdot B, B\right) d B\right)+\int_{-\frac{c q}{q^{\prime}-q}}^{S} g\left(S, \frac{c}{q^{\prime}-q}\right) d S .
\end{array}
$$

Third, the model predicts that the share of women who have an abortion may rise or fall. The share of women who have an abortion after EC is introduced is:

$$
q^{\prime} \cdot \int_{\underline{B}}^{-A} \int_{c+q^{\prime} \cdot A}^{\bar{S}} g(S, B) d S d B .
$$


This number may be larger or smaller than the number of abortions without EC. Abortion will only decrease if:

$$
\frac{q^{\prime}}{q}<\frac{\int_{\underline{B}}^{-A} \int_{q A}^{\bar{S}} g(S, B) d S d B}{\int_{\underline{B}}^{-A} \int_{c+q^{\prime} A}^{\bar{S}} g(S, B) d S d B}<1 .
$$

For an increase in the price, the comparative statics are much simpler and indicate that a lower price of EC will increase abortions since the derivative is given by:

$$
-q^{\prime} \cdot \int_{\underline{B}}^{-A} g\left(S, c+q^{\prime} \cdot A\right) d S<0 .
$$

Expansions of access to EC will unambiguously increase the number of abortions as long as abortions are more expensive than EC. On the one hand, the availability of EC induces more women to have sex. Some of these women are those who would want an abortion if EC fails. This mechanism thus raises the abortion rate. On the other hand, abortion will only now be needed when EC fails, and thus the availability of EC reduces the abortion rate. When the cost of EC $(c)$ decreases, this second effect is not present. Based on the assumptions of the model, all women who were previously pursuing abortion were already consuming EC. Thus the only effect of a decrease in $c$ is to increase the number of women who use EC. And, because EC is not foolproof, for some women, EC will fail and lead to more abortions. This result would not hold if, for some women, abortion is actually cheaper than EC, in which case, the effect of lowering $c$ would be ambiguous again.

Finally, the model predicts that the number of births may rise or fall. Births will fall if:

$$
\frac{q^{\prime}}{q}<\frac{\int_{-A}^{\frac{c}{q^{\prime}-q}} \int_{-q B}^{\bar{S}} g(S, B) d S d B}{\int_{-A}^{\frac{c}{q^{\prime}-q}} \int_{c-q^{\prime} B}^{\bar{S}} g(S, B) d S d B}<1
$$


An expansion of access will also have an uncertain impact since the derivative is given by:

$$
-q^{\prime} \cdot \int_{-A}^{\frac{c}{q^{\prime}-q}} g\left(c-q^{\prime} \cdot B, B\right) d B+\int_{-\frac{c q}{q^{\prime}-q}}^{\bar{S}} g\left(S, \frac{c}{q^{\prime}-q}\right) d S
$$


Figure I.The Effect of Pharmacy-Access Laws on Natality

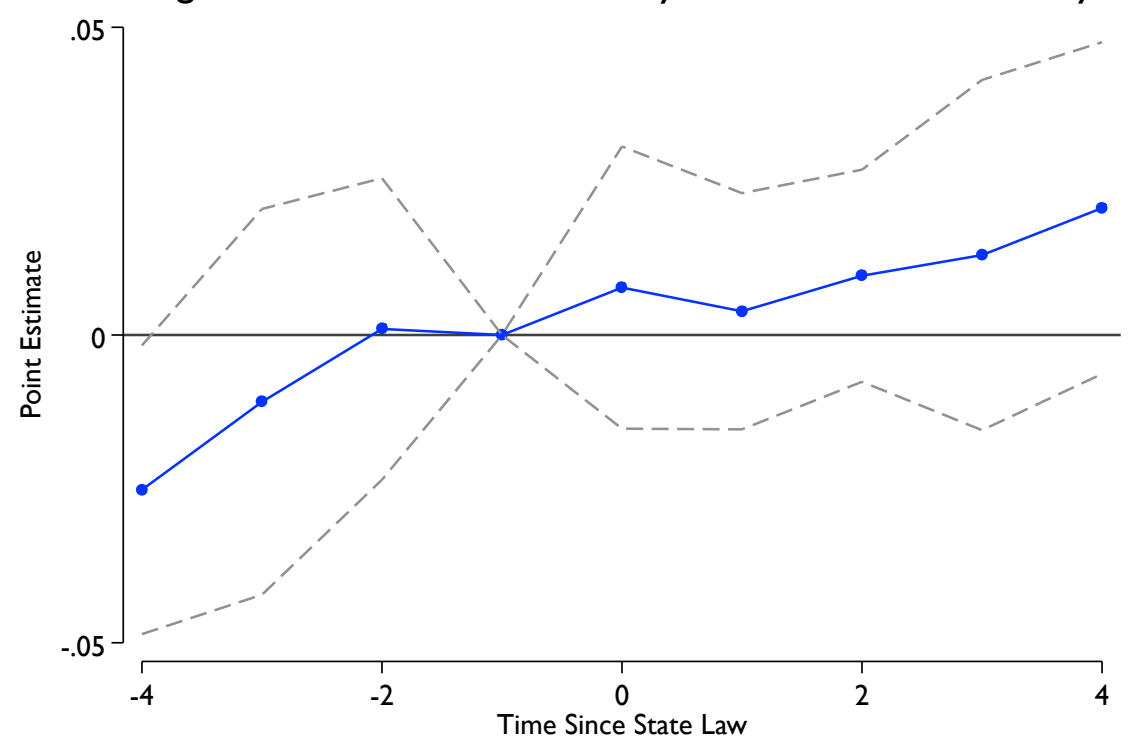

Figure 2. Sales of EC by Week

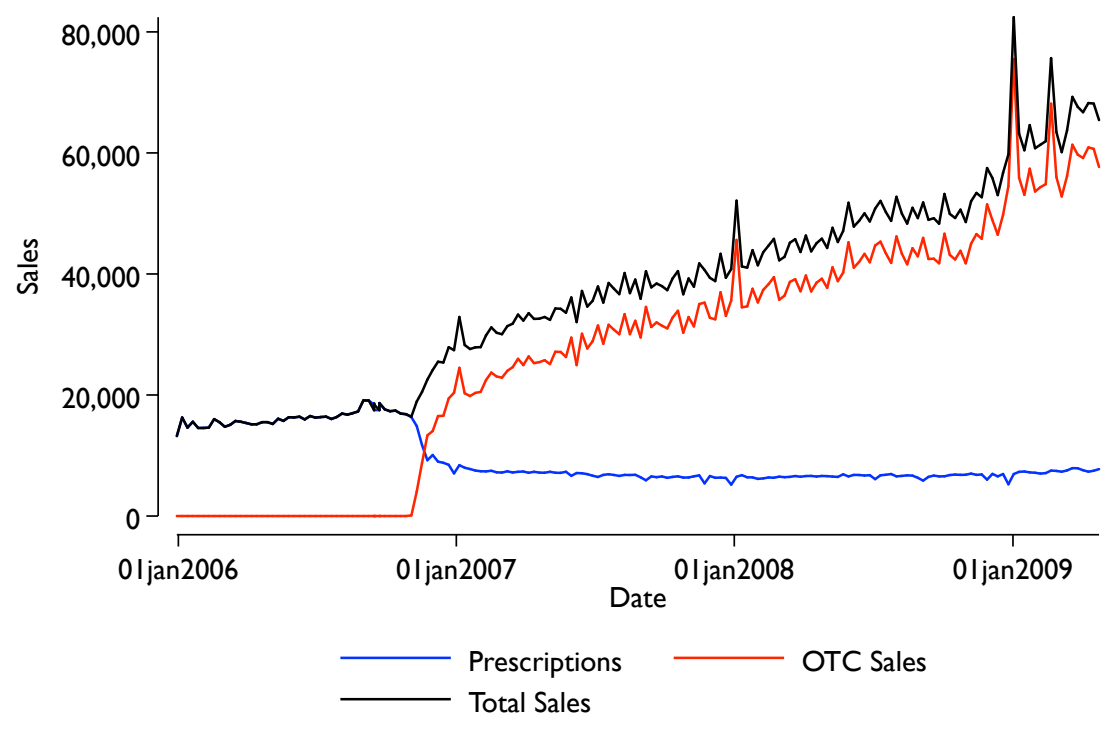


Figure 3. ED Visits in Entire HCUP Sample

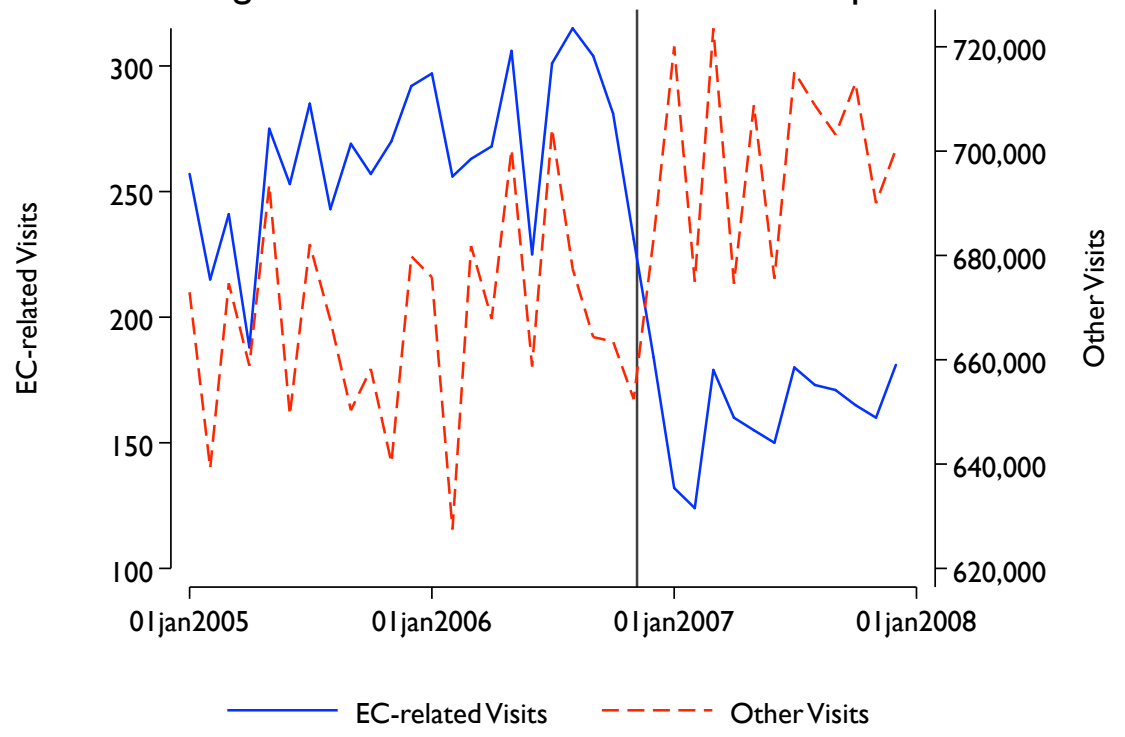

Figure 4. EDVisits in New Jersey

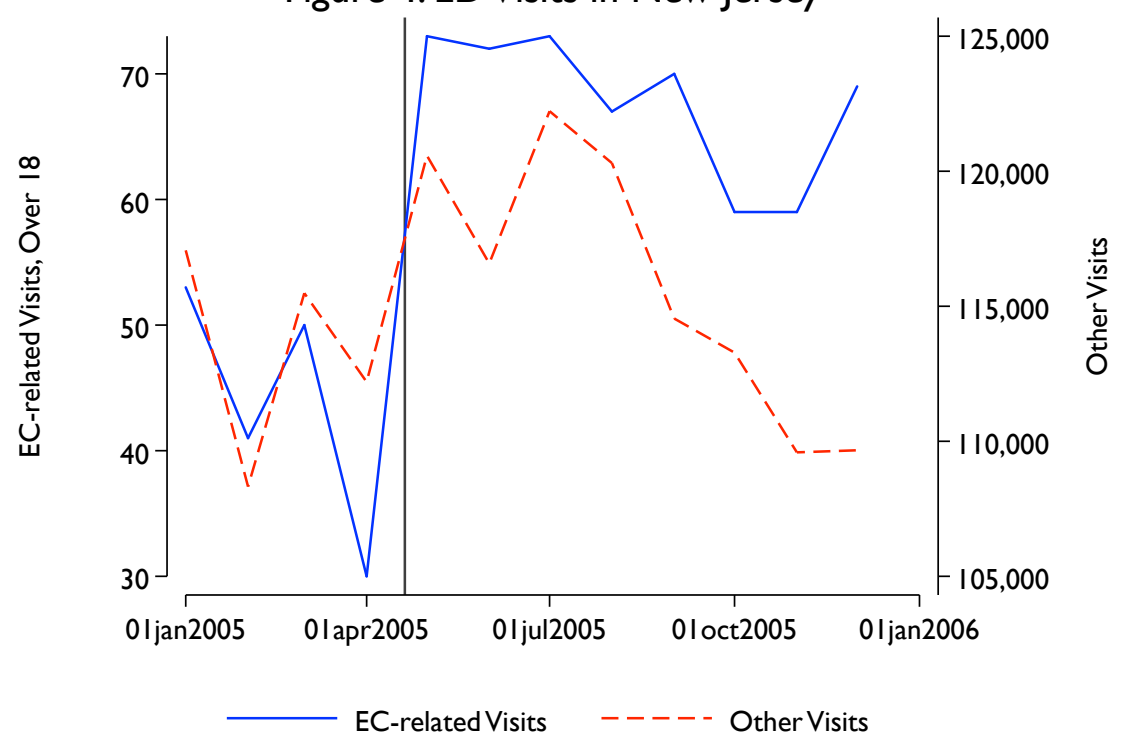


Figure 5. Effect of Pharmacy-Access Laws on Reports of Sexual Assaults

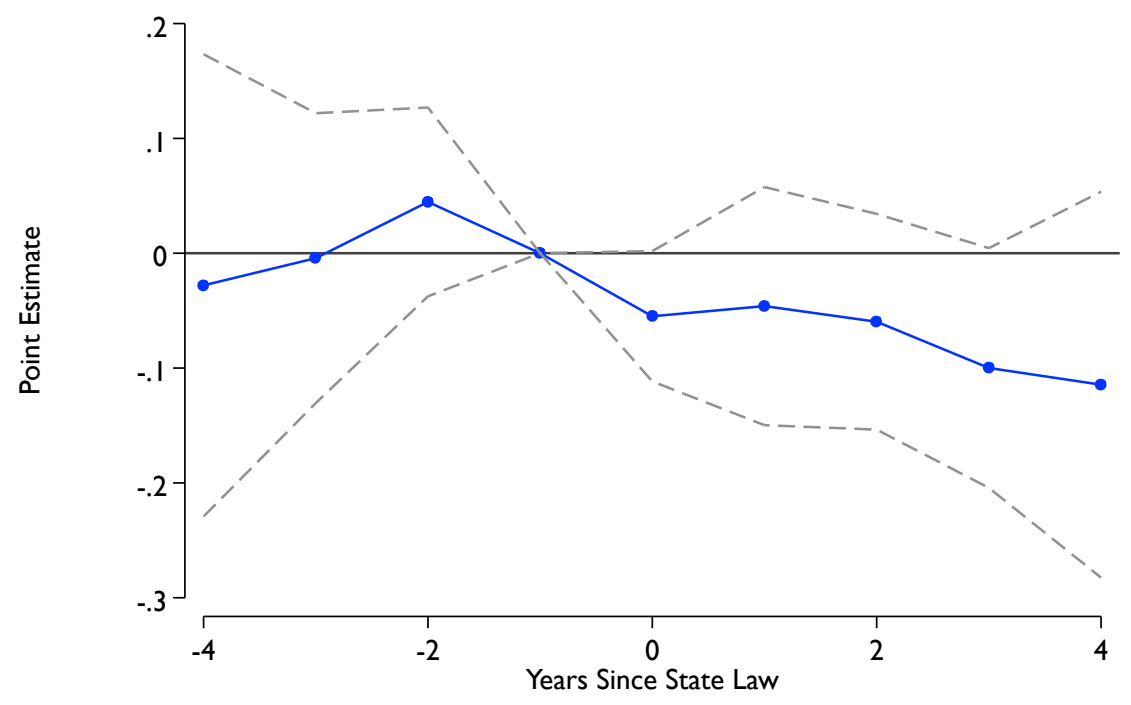

Figure 6. Sexual Assaults Visits in HCUP Sample

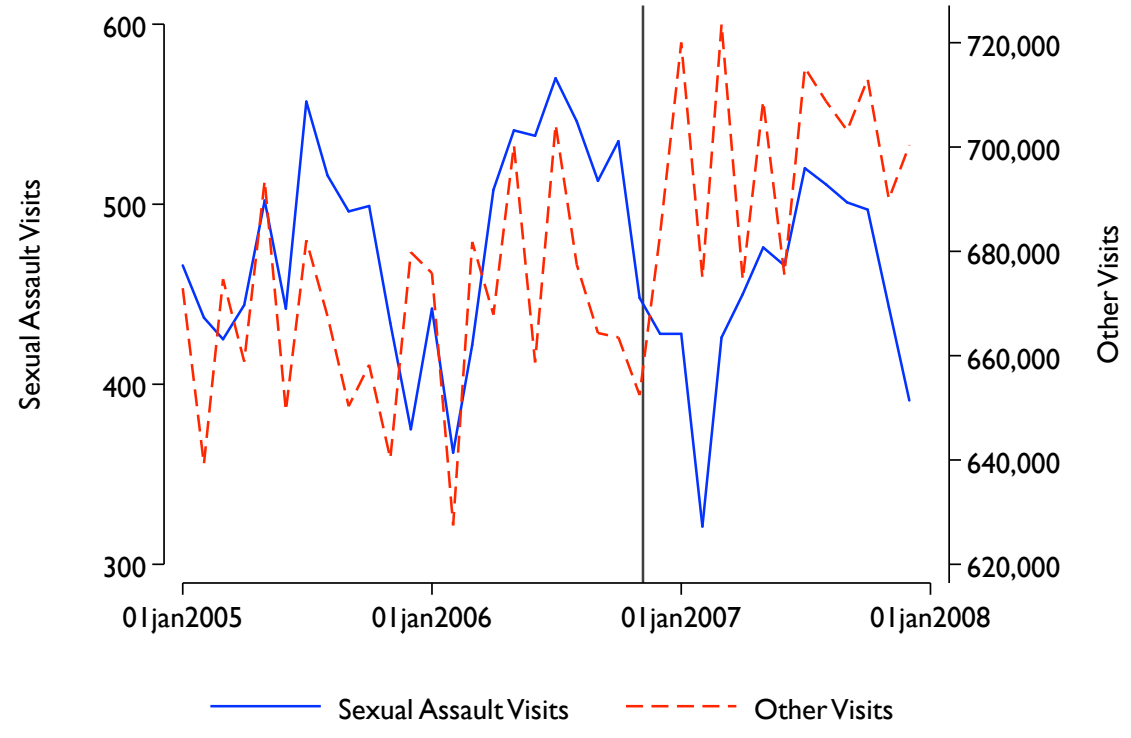


Table I. State Laws

\begin{tabular}{|c|c|c|c|c|}
\hline State or region & Pharmacy-Access Law & Pharmacy-Access Type & ED-Access Law & ED-Access Type \\
\hline Alaska & 25-Apr-2002 & Collaborative practice & & \\
\hline Arkansas & & & 9-Apr-2007 & inform \\
\hline California & I-Jan-2002 & State-approved protocol* & I-Jan-2003 & provide \\
\hline Colorado & & & I5-Mar-2007 & inform \\
\hline Connecticut & & & I-Oct-2007 & provide \\
\hline Hawaii & 24-Jun-2003 & Collaborative practice & & \\
\hline Illinois & & & I-Jan-2002 & inform \\
\hline Maine & 3-Mar-2004 & State-approved protocol** & & \\
\hline Massachusetts & I5-Sep-2005 & Collaborative practice & |4-Dec-2005 & provide \\
\hline Minnesota & & & I-Aug-2007 & provide \\
\hline New Hampshire & I5-Aug-2005 & Collaborative practice & & \\
\hline New Jersey & & & 20-Apr-2005 & provide \\
\hline New Mexico & I5-May-2003 & State-approved protocol & I-Oct-2003 & provide \\
\hline New York & & & 31 -Jan-2004 & provide \\
\hline Ohio & & & $31-M a r-2003$ & recommendation $\dagger$ \\
\hline Oregon & & & I-Jan-2008 & provide \\
\hline Pennsylvania & & & 26-Jan-2008 & provide $* * * * *$ \\
\hline South Carolina & & & \multicolumn{2}{|c|}{ 19-Jun-2005 pay (but not inform) $\dagger$} \\
\hline Texas & & & I-Sep-2005 & inform \\
\hline Utah & & & 25-Mar-2009 & provide \\
\hline Vermont & 29-Mar-2006 & Collaborative practice & & \\
\hline Washington & I-Jul-I997 & Collaborative practice ${ }^{* * *}$ & I3-Jun-2002 & provide \\
\hline Washington, DC & & & 25-Mar-2009 & provide \\
\hline Wisconsin & & & 28-Mar-2008 & provide \\
\hline National & 24-Aug-2006 & 18 and over only**** & & \\
\hline
\end{tabular}

* Legislation initially allowed collaborative practice only, but was expanded to state protocol 10/1/03.

** Hybrid model: collaboration required but not regulated. Listed as state protocol by Guttmacher.

*** Initially, a two-year pilot program building on state's existing collaborative practice law for some drugs.

**** Expanded to 17-year-olds on April 22, 2009.

$* * * * *$ Includes conscience exemption.

† These states are not considered "access" states by Guttmacher, and so we exclude in all specifications.

Note: Dates denote effective date if available, legislation signing date if effective date unknown, and adoption by legislature date if signing date unknown.

Sources: National Conference of State Legislatures; state legislative records; Guttmacher Institute; Lexis Nexis and Google news search. 
Table 2: Effect of EC-Related Laws on Natality

Dependent Variable:The logarithm of births for the given sample

\begin{tabular}{|c|c|c|c|c|}
\hline & (I) & (2) & (3) & (4) \\
\hline \multirow[t]{2}{*}{ Sample: } & $\begin{array}{r}\text { All } \\
\text { Women }\end{array}$ & $\begin{array}{r}\text { Women } \\
\text { under age } 18\end{array}$ & $\begin{array}{r}\text { Women } \\
\text { aged } 18-30\end{array}$ & $\begin{array}{l}\text { Women aged } \\
30 \text { plus }\end{array}$ \\
\hline & \multicolumn{3}{|c|}{ A: State Law Changes, 1995-2006 } & \\
\hline Passed ED-Access & -0.004 & -0.020 & 0.003 & -0.004 \\
\hline \multirow[t]{2}{*}{ Law } & $(0.010)$ & $(0.020)$ & $(0.008)$ & $(0.016)$ \\
\hline & [0.685] & {$[0.3 \mathrm{II}]$} & [0.702] & [0.808] \\
\hline Passed Pharmacy- & 0.014 & 0.014 & 0.022 & 0.009 \\
\hline \multirow[t]{2}{*}{ Access Law } & $(0.008)$ & $(0.020)$ & $(0.007)$ & $(0.013)$ \\
\hline & {$[0.100]$} & [0.465] & [0.004] & {$[0.5 \mid 2]$} \\
\hline Mean of Dep.Var. & $6,574.8$ & 269.5 & $4,257.9$ & $2,047.0$ \\
\hline \multirow[t]{2}{*}{$R^{2}$} & 0.999 & 0.989 & 0.999 & 0.998 \\
\hline & \multicolumn{3}{|c|}{ B: FDA Policy Change, 2004-2008 } & \\
\hline No ED-Access Law & -0.001 & -0.001 & -0.002 & -0.016 \\
\hline \multirow[t]{2}{*}{$X$ Post FDA } & $(0.011)$ & $(0.023)$ & $(0.012)$ & $(0.020)$ \\
\hline & [0.904] & [0.976] & [0.882] & [0.442] \\
\hline No Pharmacy- & -0.006 & 0.036 & -0.018 & 0.008 \\
\hline Access Law X Post & $(0.017)$ & $(0.022)$ & $(0.012)$ & $(0.029)$ \\
\hline FDA & [0.7/9] & {$[0.102]$} & {$[0.123]$} & {$[0.781]$} \\
\hline Mean of Dep.Var. & $7,012.6$ & 289.6 & $4,579.3$ & $2,143.3$ \\
\hline$R^{2}$ & 0.999 & 0.990 & 0.999 & 0.998 \\
\hline
\end{tabular}

Note: For panel A, $N=7,344$ and for panel $B N=6,888$. Standard errors in parentheses are robust to auto-correlation between observations from the same state. Related $p$-values are in brackets. State fixed effects, month fixed effects, and state linear time-trends not shown. The sample consists of month by state totals of all births. The second panel excludes states which changed their legislation such that births in 2006-2008 would have been impacted. 
Table 3: Effect of EC-Related Laws on Natality for Black, Unmarried Women

Dependent Variable:The logarithm of births for the given sample

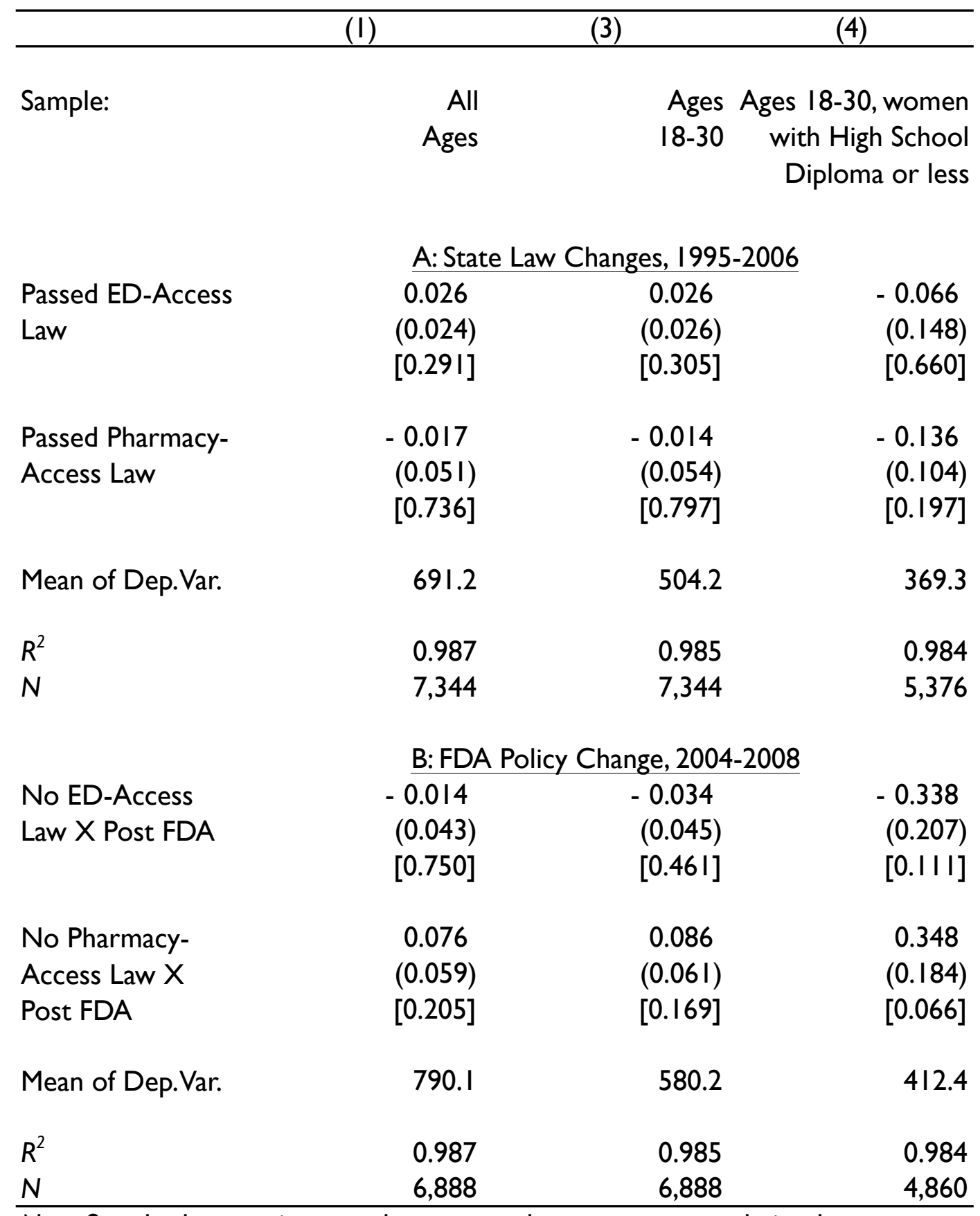

Note: Standard errors in parentheses are robust to auto-correlation between observations from the same state. Related $\mathrm{p}$-values are in brackets. State fixed effects, month fixed effects, and state linear time-trends not shown. The sample consists of month by state totals of all births. The second panel excludes states which changed their legislation such that births in 2006-2008 would have been impacted. 
Table 4: Effect of EC-Related Laws on Abortions

Dependent Variable:The logarithm of abortions for the given sample

\begin{tabular}{|c|c|c|c|c|}
\hline & (I) & (2) & (3) & (4) \\
\hline \multirow[t]{2}{*}{ Sample } & $\begin{array}{r}\text { All } \\
\text { Women }\end{array}$ & $\begin{array}{l}\text { Women } \\
\text { er age } 20\end{array}$ & $\begin{array}{r}\text { Women } \\
\text { aged } 20-29\end{array}$ & $\begin{array}{r}\text { Women } \\
\text { aged } 30 \text { plus }\end{array}$ \\
\hline & \multicolumn{4}{|c|}{ A: State Law Changes, 1995-2005 } \\
\hline Passed ED-Access & -0.052 & -0.074 & -0.043 & $-0.07 \mid$ \\
\hline Law & $\begin{array}{l}(0.059) \\
{[0.382]}\end{array}$ & $\begin{array}{l}(0.070) \\
{[0.297]}\end{array}$ & $\begin{array}{l}(0.083) \\
{[0.605]}\end{array}$ & $\begin{array}{l}(0.049) \\
{[0.152]}\end{array}$ \\
\hline Access Law & $\begin{array}{c}0.038 \\
(0.075) \\
{[0.615]}\end{array}$ & $\begin{array}{c}-0.042 \\
(0.079) \\
{[0.604]}\end{array}$ & $\begin{array}{l}-0.016 \\
(0.07 I) \\
{[0.822]}\end{array}$ & $\begin{array}{c}-0.005 \\
(0.049) \\
{[0.917]}\end{array}$ \\
\hline Mean of Dep.Var. & $16,666.8$ & $3,153.6$ & $9,294.2$ & $4,279.3$ \\
\hline$R^{2}$ & 0.987 & 0.972 & 0.986 & 0.990 \\
\hline$N$ & 505 & 501 & 504 & 503 \\
\hline & \multicolumn{4}{|c|}{ B: FDA Policy Change, 2004-2008 } \\
\hline $\begin{array}{l}\text { No ED-Access } \\
\text { Law X Post FDA }\end{array}$ & $\begin{array}{r}-0.128 \\
(0.154) \\
{[0.412]}\end{array}$ & $\begin{array}{r}-0.115 \\
(0.146) \\
{[0.434]}\end{array}$ & $\begin{array}{c}-0.027 \\
(0.111) \\
{[0.811]}\end{array}$ & $\begin{array}{r}-0.020 \\
(0.097) \\
{[0.842]}\end{array}$ \\
\hline $\begin{array}{l}\text { No Pharmacy- } \\
\text { Access Law X Post } \\
\text { FDA }\end{array}$ & $\begin{array}{l}0.170 \\
(0.135) \\
{[0.217]}\end{array}$ & $\begin{array}{l}0.194 \\
(0.118) \\
{[0.108]}\end{array}$ & $\begin{array}{c}0.056 \\
(0.080) \\
{[0.490]}\end{array}$ & $\begin{array}{c}0.021 \\
(0.060) \\
{[0.729]}\end{array}$ \\
\hline Mean of Dep.Var. & $10,944.4$ & $2,097.8$ & $6,195.5$ & $2,700.8$ \\
\hline$R^{2}$ & 0.984 & 0.960 & 0.982 & 0.988 \\
\hline N & 403 & 399 & 402 & 401 \\
\hline
\end{tabular}

Note: Standard errors in parentheses are robust to auto-correlation between observations from the same state. Related $p$-values are in brackets. State fixed effects, year fixed effects, and state linear time-trends not shown. The sample consists of year by state totals of all abortions, estimated by the CDC. The second panel excludes states which changed their legislation between 2006 and 2008. 
Table 5: Effect of EC-Related Laws on Reports of Assault

(3)

(4)

Dependent Variable:

Logarithm of Sexual Assaults per Sexual Assaults
10,000 People
Logarithm of Aggravated Assaults Aggravated Assaults per 10,000 People

\begin{abstract}
Passed ED-Access
Law

Passed Pharmacy-

Access Law

Mean of Dep.Var.

$R^{2}$

No ED-Access Law

$X$ Post FDA
\end{abstract}

No Pharmacy-Access

Law X Post FDA

Mean of Dep.Var.

A: State Law Changes, 1995-2005

$\begin{array}{cccc}0.042 & 0.215 & -0.061 & -1.638 \\ (0.027) & (0.118) & (0.038) & (1.120) \\ {[0.120]} & {[0.075]} & {[0.112]} & {[0.150]}\end{array}$

$-0.093$

$(0.036)$

[0.013]

I,839.6

0.995

0.951

$-0.308$

$(0.119)$

[0.013]

3.5
$|8,4| 1.0$

0.997
$-0.530$

(1.219)

[0.666]

30.0

0.984

\section{B: FDA Policy Change, 2004-2008}

$\begin{array}{ccc}0.036 & -0.102 & 0.038 \\ (0.054) & (0.222) & (0.032) \\ {[0.510]} & {[0.647]} & {[0.243]}\end{array}$

0.011

0.279

$-0.006$

0.190

$(0.055)$

$(0.308)$

$(0.046)$

[0.37I]

[0.897]

[0.898]

I,797.9

3.5

$18,771.6$

31.5

\begin{tabular}{l}
$R^{2}$ \\
\hline
\end{tabular}

0.941

0.995

0.977

Note: For panel A, N = 56I, for panel B, N = 585. Standard errors in parentheses are robust to autocorrelation between observations from the same state. Related $p$-values are in brackets. State fixed effects, year fixed effects, and state linear time trends not shown. The sample consists of year by state totals of all assaults reported to the FBI.The second panel excludes states which changed their legislation between 2006 and 2007. 
Appendix Table I: Effect of EC-Related Laws without Linear Time Trends Dependent Variable:The logarithm of births or abortions for the given sample

\begin{tabular}{|c|c|c|c|c|}
\hline & (I) & (2) & (3) & (4) \\
\hline Outcome: & Natality & Natality & Abortion & Abortion \\
\hline \multirow[t]{3}{*}{ Sample: } & All & Ages & All & Ages \\
\hline & Women & 18 to 30 & Women & 20 to 29 \\
\hline & \multicolumn{4}{|c|}{ A: State Law Changes, 1995-2006 } \\
\hline Passed ED-Access & -0.023 & -0.032 & 0.024 & 0.076 \\
\hline \multirow[t]{2}{*}{ Law } & $(0.020)$ & $(0.023)$ & $(0.069)$ & $(0.05 I)$ \\
\hline & [0.268] & [0.169] & {$[0.73 \mathrm{I}]$} & [0.146] \\
\hline Passed Pharmacy- & -0.013 & -0.010 & 0.224 & 0.071 \\
\hline \multirow{2}{*}{ Access Law } & $(0.012)$ & $(0.015)$ & $(0.159)$ & $(0.055)$ \\
\hline & [0.290] & [0.505] & [0.164] & {$[0.198]$} \\
\hline Mean of Dep.Var. & $6,574.8$ & $4,257.9$ & $16,666.8$ & $9,294.2$ \\
\hline$R^{2}$ & 0.998 & 0.997 & 0.965 & 0.966 \\
\hline \multirow[t]{2}{*}{ N } & 7,344 & 7,344 & 505 & 504 \\
\hline & \multicolumn{4}{|c|}{ B: FDA Policy Change, 2004-2008 } \\
\hline No ED-Access Law & 0.012 & 0.027 & -0.021 & -0.192 \\
\hline \multirow{2}{*}{$X$ Post FDA } & $(0.033)$ & $(0.031)$ & $(0.098)$ & $(0.068)$ \\
\hline & [0.709] & [0.375] & {$[0.833]$} & {$[0.008]$} \\
\hline No Pharmacy- & 0.022 & 0.014 & -0.113 & 0.033 \\
\hline Access Law X Post & $(0.030)$ & $(0.031)$ & $(0.099)$ & $(0.066)$ \\
\hline FDA & [0.467] & [0.657] & [0.264] & {$[0.617]$} \\
\hline Mean of Dep.Var. & $7,012.6$ & $4,579.3$ & $10,944.4$ & $6,195.5$ \\
\hline$R^{2}$ & 0.998 & 0.997 & 0.952 & 0.954 \\
\hline$N$ & 6,888 & 6,888 & 403 & 402 \\
\hline
\end{tabular}

Note: Standard errors in parentheses are robust to auto-correlation between observations from the same state. Related $p$-values are in brackets. State fixed effects, month fixed effects, and state linear time-trends not shown. The sample consists of month by state totals of all births. The second panel excludes states which changed their legislation such that births in 2006-2008 would have been impacted. 
Appendix Table 2: Effect of EC-Related Laws by type

Dependent Variable:The logarithm of births, abortions or sexual assault for the given sample

\begin{tabular}{|c|c|c|c|}
\hline & $(\mathrm{l})$ & $(2)$ & (3) \\
\hline Outcome: & Natality & Abortion & Sexual Assaults \\
\hline \multirow[t]{3}{*}{ Sample: } & Ages & Ages & All \\
\hline & 18 to 30 & 20 to 29 & Women \\
\hline & \multicolumn{3}{|c|}{ A: State Law Changes, 1995-2006 } \\
\hline \multirow[t]{3}{*}{ Passed ED-Access Law } & 0.002 & -0.062 & 0.050 \\
\hline & $(0.008)$ & $(0.095)$ & $(0.029)$ \\
\hline & {$[0.765]$} & {$[0.5 \mid 2]$} & [0.089] \\
\hline Passed Pharmacy-Access & 0.020 & -0.057 & -0.071 \\
\hline \multirow[t]{2}{*}{ Law-Collaborative } & $(0.009)$ & $(0.098)$ & $(0.037)$ \\
\hline & [0.026] & [0.563] & [0.059] \\
\hline Passed Pharmacy-Access & 0.025 & 0.029 & -0.117 \\
\hline \multirow[t]{2}{*}{ Law-Protocol } & $(0.010)$ & $(0.118)$ & $(0.060)$ \\
\hline & [0.021] & [0.804] & [0.055] \\
\hline$R^{2}$ & 0.999 & 0.986 & 0.995 \\
\hline \multirow[t]{2}{*}{$N$} & 7,344 & 504 & 561 \\
\hline & \multicolumn{3}{|c|}{ B: FDA Policy Change, 2004-2008 } \\
\hline No ED-Access Law X Post & -0.007 & -0.049 & 0.044 \\
\hline \multirow[t]{2}{*}{ FDA } & $(0.01 \mathrm{I})$ & $(0.109)$ & $(0.051)$ \\
\hline & {$[0.495]$} & [0.652] & [0.395] \\
\hline No Pharmacy-Access Law- & -0.031 & 0.056 & 0.035 \\
\hline \multirow[t]{2}{*}{ Collaborative $X$ Post FDA } & $(0.012)$ & $(0.080)$ & $(0.075)$ \\
\hline & {$[0.012]$} & [0.490] & [0.640] \\
\hline No Pharmacy-Access Law- & 0.003 & 0.101 & -0.021 \\
\hline \multirow[t]{2}{*}{ Protocol X Post FDA } & $(0.010)$ & $(0.080)$ & $(0.04 I)$ \\
\hline & {$[0.765]$} & {$[0.2 \mid 4]$} & {$[0.6 \mid 4]$} \\
\hline$R^{2}$ & 0.999 & 0.982 & 0.994 \\
\hline$N$ & 6,888 & 402 & 585 \\
\hline
\end{tabular}

Note: Standard errors in parentheses are robust to auto-correlation between observations from the same state. Related $p$-values are in brackets. State fixed effects and month fixed effects not shown. The sample consists of month by state totals of all births. The second panel excludes states which changed their legislation such that births in 2006-2008 would have been impacted. 